\title{
Focal Myocarditis after Mild COVID-19 Infection in Athletes
}

\author{
Ivana P. Nedeljkovic ${ }^{1,2, *(1)}$, Vojislav Giga ${ }^{1,2}$, Marina Ostojic ${ }^{2}$, Ana Djordjevic-Dikic ${ }^{1,2}$, Tamara Stojmenovic ${ }^{3,4}$, \\ Ivan Nikolic ${ }^{3}$, Nenad Dikic ${ }^{3,4}{ }^{(1)}$, Olga Nedeljkovic-Arsenovic ${ }^{1,5}$, Ruzica Maksimovic ${ }^{1,5}$, Milan Dobric ${ }^{1,2}$, \\ Nebojsa Mujovic ${ }^{1,2}$ and Branko Beleslin ${ }^{1,2}$
}

1 School of Medicine, University of Belgrade, 11000 Belgrade, Serbia; voja2011@yahoo.com (V.G.); skali.ana7@gmail.com (A.D.-D.); olganedeljkovic@gmail.com (O.N.-A.); dr.ruzica.maksiovic@gmail.com (R.M.); iatros007@gmail.com (M.D.); nmujovic@gmail.com (N.M.); branko.beleslin@gmail.com (B.B.)

2 Cardiology Department, University Clinical Center of Serbia, 11000 Belgrade, Serbia; drmarinaostojic@gmail.com

3 Private Practice for Sports Medicine “Vita Maxima”, 11030 Belgrade, Serbia; antictamara@hotmail.com (T.S.); nikolic.ivan6@gmail.com (I.N.); nenad.dikic@gmail.com (N.D.)

4 Faculty of Physical Culture and Sports Management, Singidunum University, 11000 Belgrade, Serbia

5 Radiology and MRI Department, University Clinical Center of Serbia, 11000 Belgrade, Serbia

* Correspondence: ivannanedeljkovic@yahoo.com; Tel.: +381-632-326-96

check for updates

Citation: Nedeljkovic, I.P.; Giga, V.; Ostojic, M.; Djordjevic-Dikic, A.; Stojmenovic, T.; Nikolic, I.; Dikic, N.; Nedeljkovic-Arsenovic, O.;

Maksimovic, R.; Dobric, M.; et al. Focal Myocarditis after Mild COVID-19 Infection in Athletes. Diagnostics 2021, 11, 1519. https:// doi.org/10.3390/diagnostics11081519

Academic Editor: Oliver Faust

Received: 10 August 2021

Accepted: 20 August 2021

Published: 23 August 2021

Publisher's Note: MDPI stays neutral with regard to jurisdictional claims in published maps and institutional affiliations.

\begin{abstract}
COVID-19 infection in athletes usually has a milder course, but in the case of complications, myocarditis and even sudden cardiac death may occur. We examined an athlete who felt symptoms upon returning to training after asymptomatic COVID-19 infection. Physical, laboratory, and echocardiography findings were normal. The cardiopulmonary exercise test was interrupted at submaximal effort due to severe dyspnea in the presence of reduced functional capacity in comparison to previous tests. Cardiac magnetic resonance (CMR) detected the focal myocarditis. After three months of recovery, CMR still revealed the presence of focal myocarditis and the persistence of decreased functional capacity. This case raises the question of screening athletes even after asymptomatic forms of COVID-19 infection.
\end{abstract}

Keywords: COVID-19 infection; athlete; return to play; myocarditis; cardiac magnetic resonance

\section{Introduction}

Competitive sports, including training and matches, create favorable conditions for the spread of SARS-CoV-2 virus, which causes COVID-19 infection [1]. Recent recommendations for the evaluation of athletes who test positive for COVID-19 prior to return to play (RTP) were based on the presence of symptoms, electrocardiography (ECG), cardiac biomarkers, and echocardiography or cardiac magnetic resonance (CMR) imaging for advanced assessment [2,3]. Although COVID-19 infection in athletes usually has a milder course, in the case of complications, myocarditis and even sudden cardiac death may occur, as with myocarditis of other causes [4]. However, for athletes after mild or asymptomatic COVID-19 infections, no pre-RTP testing was scheduled. This pointed to the need to consider screening methods, but also that the recommendations must be applied flexibly due to the insidious course of this new disease, as recent CMR studies demonstrated a variable frequency of cardiac involvement in patients who recovered from asymptomatic to mild COVID-19 [5-7].

This case may not be unique, but it shows all of the diagnostic steps necessary to reach a diagnosis in an athlete after asymptomatic COVID-19 infection.

\section{Case Report}

A 32-year-old athlete received a positive PCR test for COVID-19 during routine testing of the entire team. Laboratory analysis showed normal findings (Table 1). As he was 
asymptomatic, isolation of 15 days was recommended. He received a permit to return to training once the isolation of 15 days was over and after confirmation of another negative COVID-19 test result. At the control visit, laboratory findings were still normal (Table 1).

Table 1. Laboratory findings during COVID-19 infection and after a 15-day isolation.

\begin{tabular}{|c|c|c|c|}
\hline Parameter & Baseline & After Two Weeks & Normal Range \\
\hline Leucocytes $\left(10^{9} \mathrm{~g} / \mathrm{L}\right)$ & 6.4 & 8.1 & $3.4-9.7$ \\
\hline Lymphocytes $\left(10^{9} \mathrm{~g} / \mathrm{L}\right)$ & 2.4 & 3.3 & $1.2-3.4$ \\
\hline Eosinophils $\left(10^{9} \mathrm{~g} / \mathrm{L}\right)$ & 0.20 & 0.40 & $0.0-0.1$ \\
\hline Red blood cells $\left(10^{9} \mathrm{~g} / \mathrm{L}\right)$ & 5.56 & 5.23 & $3.86-5.08$ \\
\hline Hemoglobine $(\mathrm{g} / \mathrm{L})$ & 156 & 145 & $119-157$ \\
\hline Platelets $\left(10^{9} \mathrm{~g} / \mathrm{L}\right)$ & 220 & 165 & $158-424$ \\
\hline $\mathrm{Fe}(\mathrm{mcmol} / \mathrm{L})$ & 15.8 & 15.4 & $7.0-28.0$ \\
\hline Ferritin (mcg/L) & 16.3 & 17 & $4.6-204.0$ \\
\hline Creatinine (mcmol/L) & 71 & 75 & $45-84$ \\
\hline C-reactive protein $(\mathrm{mg} / \mathrm{L})$ & 4 & 3.2 & $0.00-10.0$ \\
\hline $\mathrm{BNP}^{1}(\mathrm{pg} / \mathrm{mL})$ & 8 & 7 & $0-89$ \\
\hline hs Troponin ${ }^{2} \mathrm{~T}(\mu \mathrm{g} / \mathrm{L})$ & 7 & 8 & $<10$ \\
\hline Interleukin $6(\mathrm{pg} / \mathrm{mL})$ & 5 & 4 & $0-7$ \\
\hline D-dimer (mg/L FEU) & 0.28 & 0.36 & $<0.50$ \\
\hline $\mathrm{K}^{3}(\mathrm{mmol} / \mathrm{L})$ & 4.5 & 4.2 & $3.5-5.1$ \\
\hline $\mathrm{Na}^{4}(\mathrm{mmol} / \mathrm{L})$ & 140 & 135 & \\
\hline Lactate dehydrogenase (U/L) & 376 & 350 & $220-460$ \\
\hline $\operatorname{AST}^{5}(\mathrm{U} / \mathrm{L})$ & 24 & 19 & $0-37$ \\
\hline $\mathrm{ALT}^{6}(\mathrm{U} / \mathrm{L})$ & 18 & 14 & $0-41$ \\
\hline
\end{tabular}

${ }^{1} \mathrm{BNP}$ - brain natriuretic peptide; ${ }^{2}$ hs Troponin T—high sensitivity troponin $\mathrm{T} ;{ }^{3} \mathrm{~K}$-serum potassium; ${ }^{4} \mathrm{Na}$ - $\operatorname{serum}$ sodium; ${ }^{5} \mathrm{AST}$ aspartate aminotransferase; ${ }^{6}$ ALT—alanine aminotransferase.

However, during the exercise, he suddenly became dyspneic and had a feeling of dizziness, which is why he was referred to a cardiologist. Physical examination showed normal findings and the resting ECG was recorded (Figure 1). The ECG showed a pathological finding compared to earlier routine controls, suggesting that the COVID-19 infection was not completely silent.

Although the acute phase of the infection itself was asymptomatic, ECG changes with an accelerated heartrate and the presence of PVC indicated an abnormality. We performed a treadmill cardiopulmonary exercise test (CPET) to assess functional capacity, hemodynamic response, and possible arrhythmias in exertion. We used the continuous sports ramp protocol. Expiratory gases were collected on a breath-by-breath basis and analyzed by metabolic cart (Schiller CS 200, Germany). The ventilatory anaerobic threshold (VAT) was determined by the "V-slope" analysis on oxygen consumption $\left(\mathrm{VO}_{2}\right)$ vs. carbon dioxide production $\left(\mathrm{VCO}_{2}\right)$. The values of the $\mathrm{VO}_{2}$ at $\mathrm{VAT}$ and at peak exercise (peak $\mathrm{VO}_{2}$ ) are expressed as $\mathrm{mL} \mathrm{O}_{2} / \mathrm{kg} / \mathrm{min}$ during the $30 \mathrm{~s}$ in which the examined event occurred, and were printed using rolling averages every $10 \mathrm{~s}$. The ventilatory efficiency $\left(\mathrm{VE} / \mathrm{VCO}_{2}\right)$ slope was measured by excluding data points after the onset of maximal hyperventilation at the maximal effort. The respiratory exchange ratio (RER) $\geq 1.20$ at the end of CPET was considered as the achievement of maximal effort. The test was interrupted at submaximal effort (RER = 1.06) due to the sudden onset of severe dyspnea, with achievement of only $76 \%$ of the predicted $\mathrm{maxVO}_{2}$ in the presence of normal ventilatory parameters. Compared with the previous test, which achieved maximum results, this result showed a decrease of exercise capacity after COVID-19 infection (Table 2). 


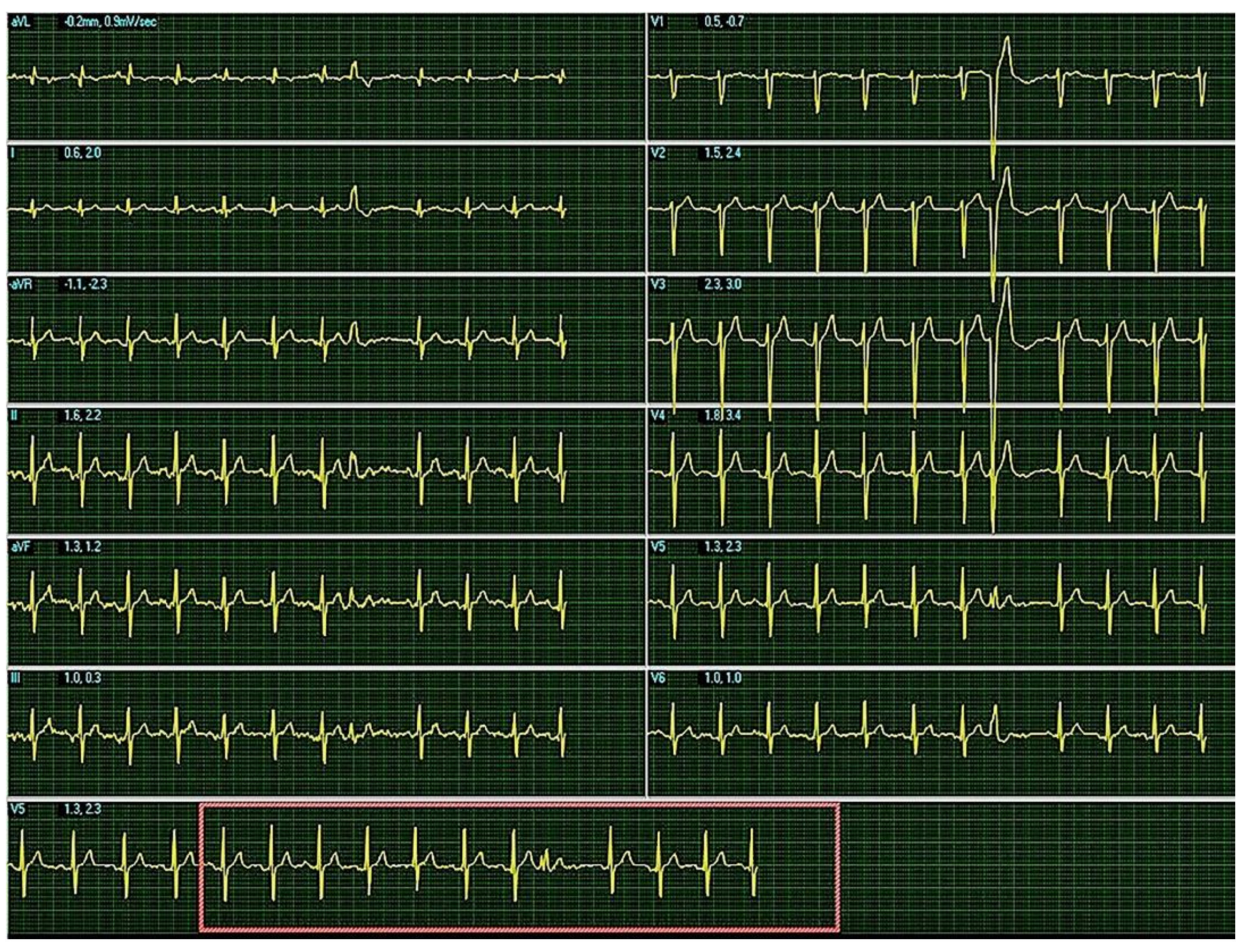

Figure 1. Resting ECG: sinus rhythm, heartrate = 95/min, AxQRS + 70, narrow QRS complex, R/S in leads D2, D3, aVF, r/S in leads V2, V3 with unifocal premature ventricular contraction with left bundle branch block morphology.

Table 2. Parameters of cardiopulmonary exercise testing before COVID-19 infection in the athlete and after two weeks and three months of follow-up.

\begin{tabular}{|c|c|c|c|}
\hline Variable & $\begin{array}{l}\text { Before COVID-19 } \\
\text { Infection }\end{array}$ & $\begin{array}{c}\text { After Two Weeks of } \\
\text { Follow-Up }\end{array}$ & $\begin{array}{c}\text { After Three Months of } \\
\text { Follow-Up }\end{array}$ \\
\hline Test duration (s) & 900 & 490 & 600 \\
\hline Resting heart rate (bpm) & 50 & 80 & 85 \\
\hline Peak heart rate (bpm) & 177 & 166 & 160 \\
\hline Resting systolic blood pressure (mmHg) & 132 & 140 & 130 \\
\hline Peak systolic blood pressure $(\mathrm{mmHg})$ & 140 & 160 & 150 \\
\hline Resting diastolic blood pressure (mmHg) & 75 & 75 & 70 \\
\hline Peak diastolic blood pressure $(\mathrm{mmHg})$ & 80 & 90 & 70 \\
\hline $\operatorname{AT~VO}_{2}{ }^{1}(\mathrm{~mL} / \mathrm{kg} / \mathrm{min})$ & 26 & 23.1 & 22 \\
\hline Peak $\mathrm{VO}_{2}(\mathrm{~mL} / \mathrm{kg} / \mathrm{min})$ & 45 & 32.2 & 31.4 \\
\hline$\%$ Predicted $\mathrm{VO}_{2}$ & 106 & 76 & 74 \\
\hline Peak $\mathrm{VO}_{2} / \mathrm{HR}^{2}$ (mL/beat) & 23 & 18 & 19 \\
\hline $\mathrm{VE} / \mathrm{VCO}_{2}$ slope $^{3}$ & 24 & 27 & 20 \\
\hline Resting PetCO ${ }_{2}^{4}(\mathrm{mmHg})$ & 31 & 30 & 33 \\
\hline Peak PetCO $2(\mathrm{mmHg})$ & 49 & 48 & 45 \\
\hline METs $^{5}$ & 11.6 & 9.2 & 8.9 \\
\hline RER $^{6}$ & 1.2 & 1.06 & 1.2 \\
\hline
\end{tabular}

${ }^{1} \mathrm{AT} \mathrm{VO}_{2}$ - oxygen consumption at the ventilatory anaerobic threshold ${ }^{2} \mathrm{VO}_{2} / \mathrm{HR}$-oxygen pulse; ${ }^{3} \mathrm{VE} / \mathrm{VCO}_{2}$ slope-minute ventilation to carbon dioxide production relationship slope; ${ }^{4} \mathrm{PetCO}_{2}$ - end-tidal carbon dioxide; ${ }^{5} \mathrm{METs}$-metabolic equivalents; ${ }^{6} \mathrm{RER}-\mathrm{respiratory}$ exchange ratio.

The baseline ECG before CPET is presented on Figure 2. ECG during the test showed that more frequent exercise induced premature ventricular complexes (PVCs) (Figure 3). 


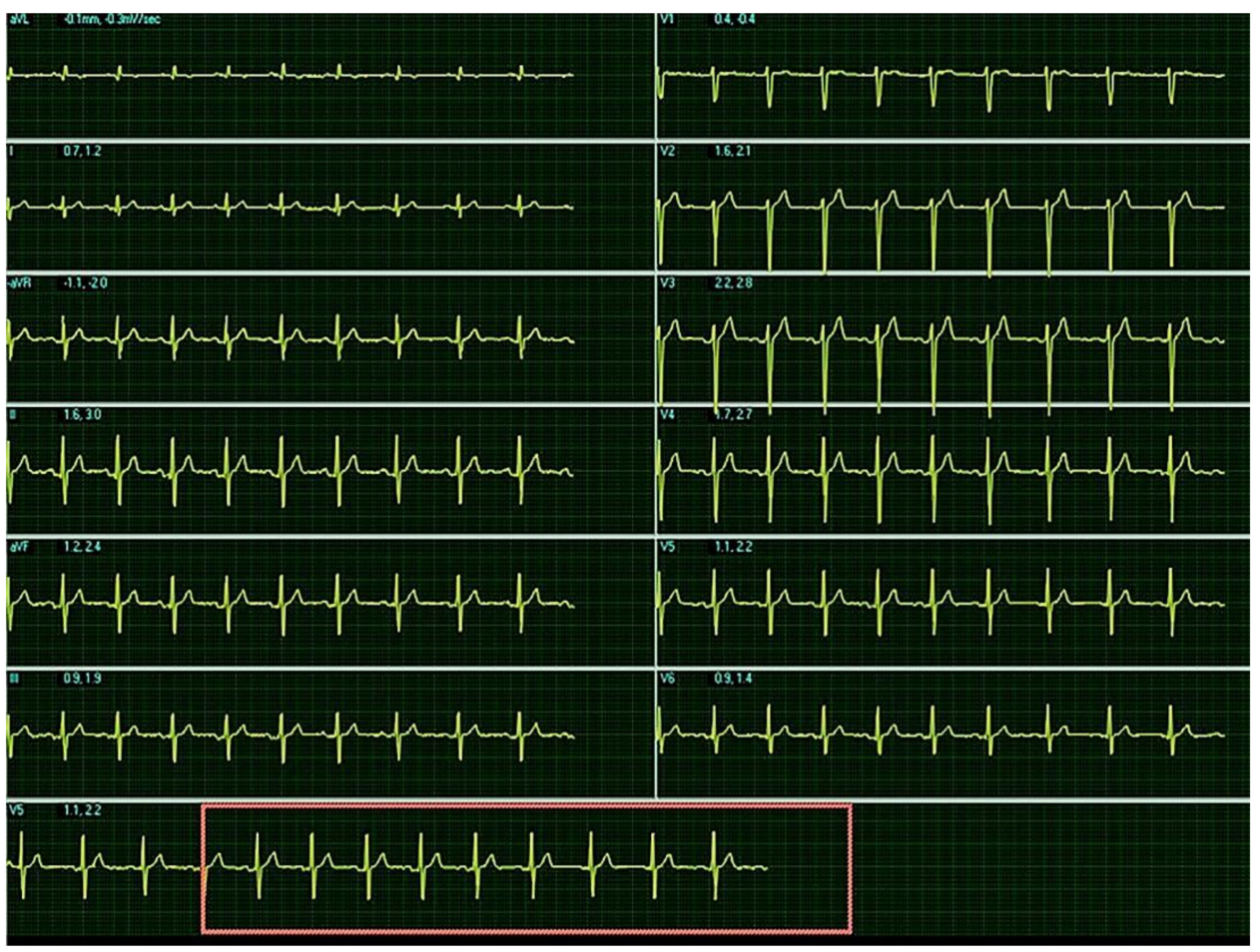

Figure 2. Baseline ECG before the cardiopulmonary test: sinus rhythm, heartrate $=80 / \mathrm{min}, \mathrm{AxQRS}+$ 70, narrow QRS complex, R/S in leads D2, D3, aVF, r/S in leads V2, V3 without signs of hypertrophy.

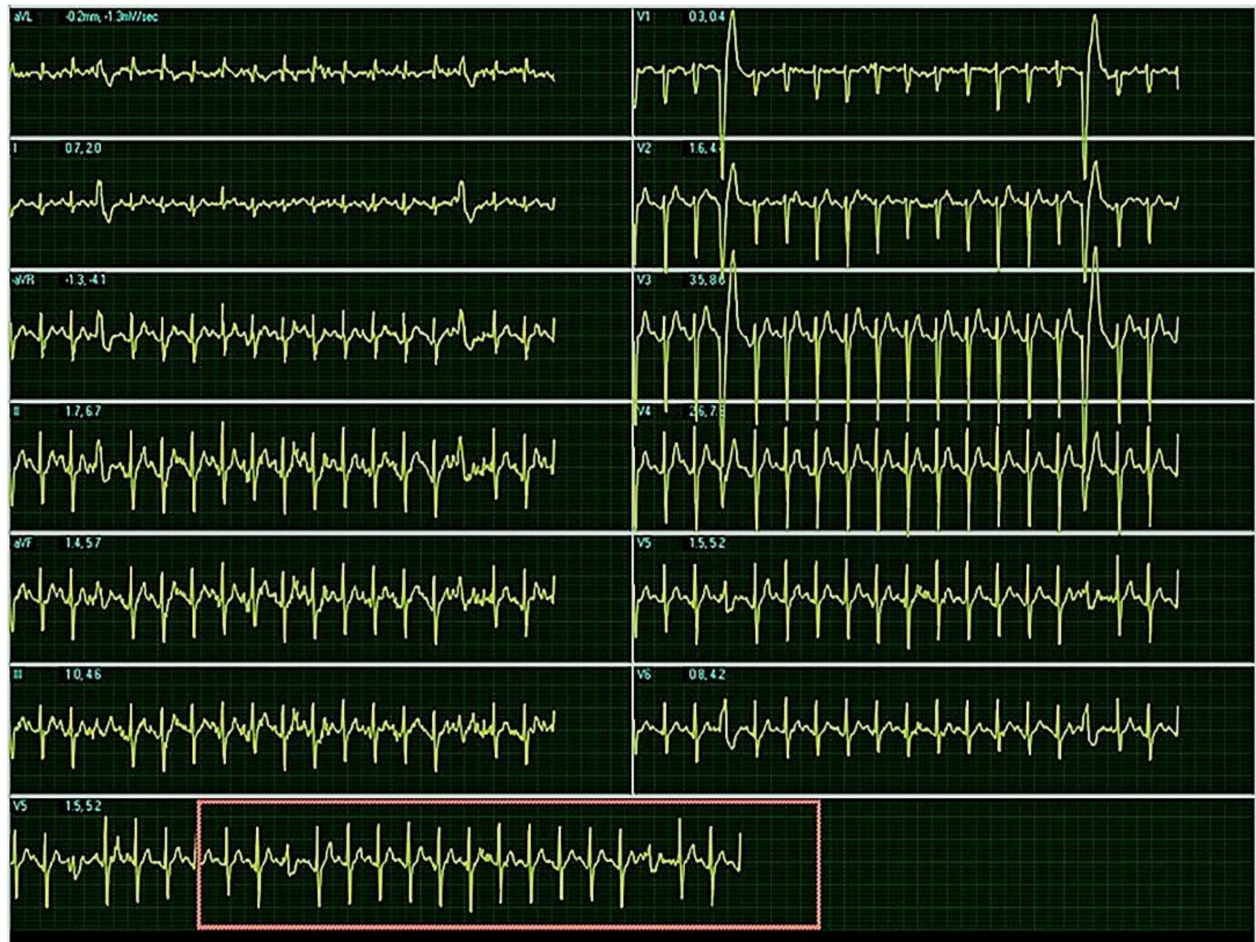

Figure 3. Electrocardiogram during cardiopulmonary test: sinus tachycardia, heartrate $=166 / \mathrm{min}$, AxQRS + 70, narrow QRS complex, R/S in leads D2, D3, aVF, r/S in leads V2, V3 with unifocal premature ventricular complexes with left bundle branch block morphology. Ambulatory 24-h ECG monitoring recorded 1535 PVCs and several episodes of trigeminia.

Cardiovascular magnetic resonance (CMR) was performed as the current non-invasive imaging gold standard for assessing cardiac anatomy, function, and more importantly, 
myocardial tissue characterization. We used standard planes with functional TrueFISP and morphological turbo spin-echo sequences. There were no signs of tissue edema in native images. Ten minutes after the application of contrast, we managed to detect late gadolinium enhancement (LGE) in the mid-lateral left ventricular (LV) wall (Figure 4a). Parametric myocardial mapping was also performed to add incremental diagnostic and prognostic value to conventional tissue characterization techniques in the evaluation of potential COVID-related myocardial diseases (Figure $4 b$ ).

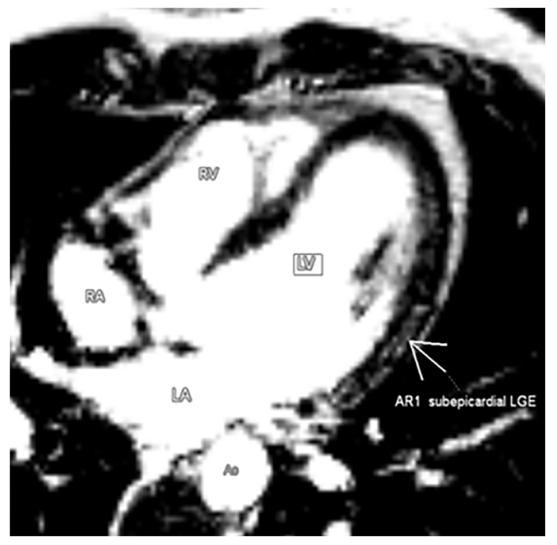

(a)

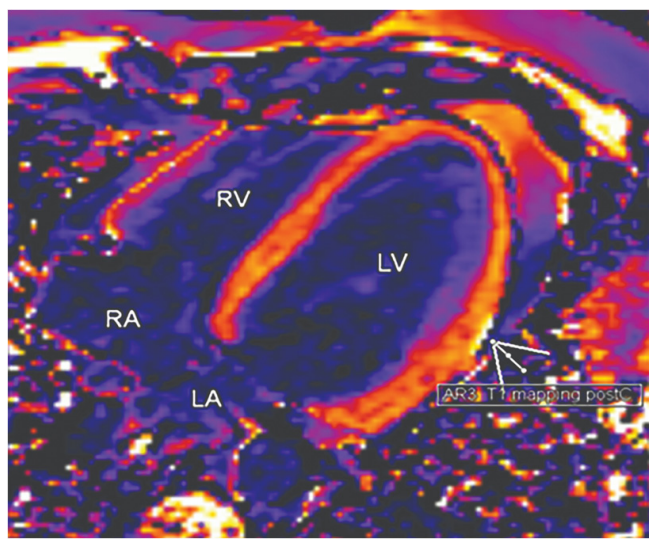

(b)

Figure 4. Cardiac magnetic resonance. (a) Four-chamber view ten minutes from the application of gadolinium with detection of the late gadolinium enhancement in the mid-lateral left ventricular wall. (b) Myocardial mapping (four-chamber view) showed elevated T1 signals of the mid-lateral left ventricular wall, with the enhancement of the adjacent pericardium also confirming the presence of pericarditis.

Prescribed therapy included ibuprofen, bisoprolol, and coenzyme Q-10, with the cessation of training for the next three months.

After three months of follow-up, the control CMR showed preserved left and right ventricular function (LVEF 61\%, RVEF 65\%) with a homogeneous myocardial structure in native sequences. There were persistent postcontrast pathological findings of the medial part of the LV lateral wall in terms of myocarditis sequelae (Figure 5a,b).

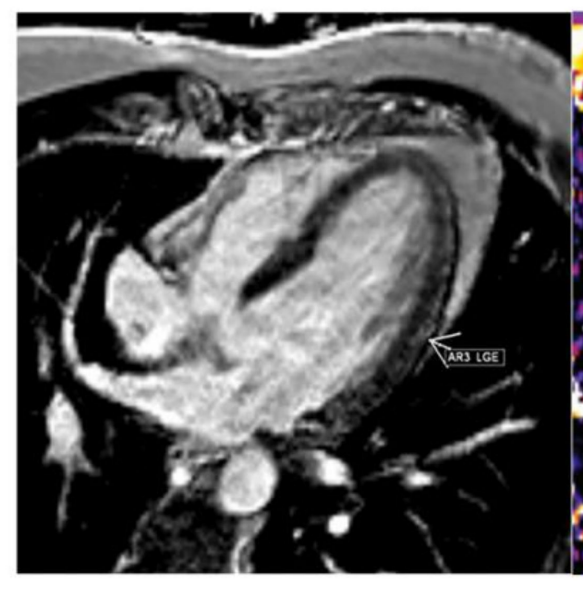

a)

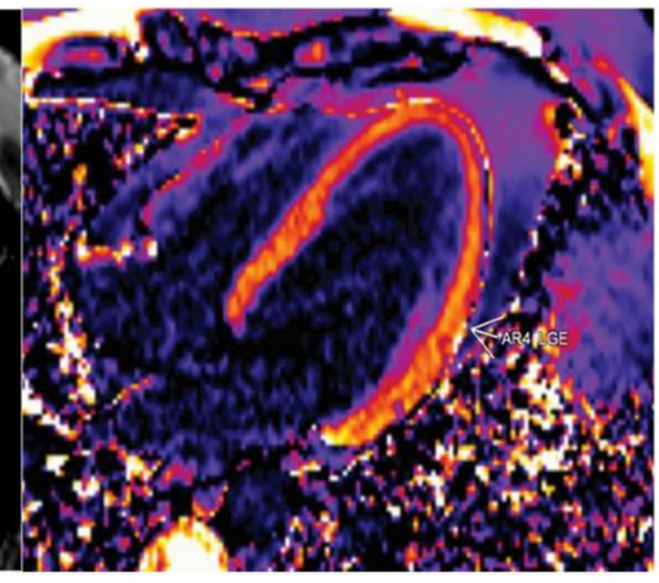

b)

Figure 5. Control cardiac magnetic resonance three months after COVID-19 infection. (a) Persistence of late gadolinium enhancement in the basal and mid-lateral left ventricular wall. (b) Control CMR mapping detected increased values of postcontrast T2 subepicardial in the basal and medial part of the LV lateral wall in terms of myocarditis sequelae. The focal involvement of the pericardium along the lateral wall of the left ventricle can also be seen. 
The control CPET reached the maximal effort (RER 1.2) without improvement in peak $\mathrm{VO}_{2}$ in the presence of normal ventilator parameters (Table 2). Further interruption of training has been recommended the next three months.

\section{Discussion}

Although hospitalization for acute COVID-19 infection is uncommon in athletes, it may result in myocarditis, even in the absence of symptoms with the rate of 2 to $3 \%$ [1-3]. However, in overt myocarditis, exercise may have a potentially pro-arrhythmic effect, which may lead to sudden cardiac death due to accelerated inflammation and cellular necrosis $[3,4]$. Routine cardiac testing after asymptomatic COVID-19 infection has not been recommended, but the occurrence of symptoms after RTP requires meticulous attention [1-3]. We present the case of an athlete who experienced symptoms after RTP while the previous COVID-19 infection itself had been silent.

Reduced functional capacity during CPET in athletes indicates the need for evaluation with CMR, as it may detect the myocarditis in the form of LGE, but it does not itself represent a rationale for training restriction [8,9]. In our case with asymptomatic COVID19 infection, reduced functional capacity provided additional clinical information to the CMR findings in terms of focal myopericarditis. This is in concordance with the cohort study of Daniels et al. of 1597 US competitive athletes with CMR screening after COVID19 infection. They confirmed the role of CMR imaging for the detection of clinical and subclinical myocarditis in 2.3\% of college athletes after COVID-19 infection [10].

Complex mechanisms of impaired functional capacity after COVID-19 cannot be attributed solely to focal myocarditis, but also to tissue abnormalities in other organs, such as the lungs and kidneys, as identified by CMR [7,8], which explains the reduced peak $\mathrm{VO}_{2}$ in our athlete in the presence of normal heart and lung function. Gao et al. also proposed CPET as a useful test to distinguish the reasons of effort intolerance after COVID-19, suggesting that it can be affected not only by ventilatory inefficiency, but also by cardiac involvement [11]. Furthermore, as in our case report, the pericardial enhancement even without effusion is strongly associated with COVID-19 pathological cardiac sequalae as described by [9]. Malek et al. suggested that pathological CMR in elite athletes should not be considered restrictive for RTP in the presence of normal ECGs and laboratories after a mild COVID-19 infection. Our athlete had reduced peak $\mathrm{VO}_{2}$ even after three months of recovery [12].

Thus, in the absence of symptoms and pathological cardiac biomarkers in athletes, a careful approach is required for appropriate clinical decision-making. This case emphasizes the importance of early cardiac assessment even after asymptomatic COVID-19 infection and the need for the integrated evaluation of functional parameters (CPET) and CMR results in light of clinical findings.

Author Contributions: Conceptualization, I.P.N. and V.G.; data analysis, M.O.; cardiopulmonary test analysis, I.P.N., T.S. and I.N.; investigation and clinical follow-up, A.D.-D. and N.D.; CMR image analysis, O.N.-A. and R.M.; writing-original draft preparation, I.P.N. and M.D.; review and editing, N.M. and B.B. All authors have read and agreed to the published version of the manuscript.

Funding: This research received no external funding.

Institutional Review Board Statement: The study, as other studies with CPET, was conducted according to the guidelines of the Declaration of Helsinki, and approved by the Institutional Review Board and Ethics Committee od School of Medicine, Belgrade University for the Scientific Project No 41022-Ministry of Science, Education and Technological Development of the Republic of Serbia.

Informed Consent Statement: Informed consent was obtained from the studied athlete for clinical assessment, and written informed consent has been obtained from the patient to publish this paper.

Data Availability Statement: Not applicable. 
Acknowledgments: This case was supported by Ministry of Science, Education and Technological Development of the Republic of Serbia (Project No 41022), by technical support (equipment and materials).

Conflicts of Interest: The authors declare no conflict of interest.

\section{References}

1. Brito, D.; Meester, S.; Yanamala, N.; Patel, H.B.; Balcik, B.J.; Casaclang-Verzosa, G.; Seetharam, K.; Riveros, D.; Beto, R.J.; Balla, S.; et al. High Prevalence of Pericardial Involvement in College Student Athletes Recovering From COVID-19. JACC Cardiovasc. Imaging 2021, 14, 541-555. [CrossRef] [PubMed]

2. McKinney, J.; Connelly, K.A.; Dorian, P.; Fournier, A.; Goodman, J.M.; Grubic, N.; Isserow, S.; Moulson, N.; Philippon, F.; Pipe, A.; et al. COVID-19-Myocarditis and Return to Play: Reflections and Recommendations From a Canadian Working Group. Can. J. Cardiol. 2020, 2021, 1-10. [CrossRef]

3. Wilson, M.G.; Hull, J.H.; Rogers, J.; Pollock, N.; Dodd, M.; Haines, J.; Harris, S.; Loosemore, M.; Malhotra, A.; Pieles, G.; et al. Cardiorespiratory considerations for return-to-play in elite athletes after COVID-19 infection: A practical guide for sport and exercise medicine physicians. Br. J. Sports Med. 2020, 54, 1157-1161. [CrossRef] [PubMed]

4. Puntmann, V.O.; Carerj, M.L.; Wieters, I.; Fahim, M.; Arendt, C.; Hoffmann, J.; Shchendrygina, A.; Escher, F.; Vasa-Nicotera, M.; Zeiher, A.M.; et al. Outcomes of Cardiovascular Magnetic Resonance Imaging in Patients Recently Recovered From Coronavirus Disease 2019 (COVID-19). JAMA Cardiol. 2020, 5, 1265. [CrossRef]

5. Pelliccia, A.; Sharma, S.; Gati, S.; Bäck, M.; Börjesson, M.; Caselli, S.; Collet, J.-P.; Corrado, D.; Drezner, J.A.; Halle, M.; et al. 2020 ESC Guidelines on sports cardiology and exercise in patients with cardiovascular disease. Eur. Heart J. 2021, 42, 17-96. [CrossRef]

6. Rajpal, S.; Tong, M.S.; Borchers, J.; Zareba, K.M.; Obarski, T.P.; Simonetti, O.P.; Daniels, C.J. Cardiovascular Magnetic Resonance Findings in Competitive Athletes Recovering From COVID-19 Infection. J. AMA Cardiol. 2020, 6, 116-118. [CrossRef]

7. Clark, D.E.; Parikh, A.; Dendy, J.M.; Diamond, A.B.; George-Durrett, K.; Fish, F.A.; Slaughter, J.C.; Fitch, W.; Hughes, S.G.; Soslow, J.H. COVID-19 Myocardial Pathology Evaluation in Athletes With Cardiac Magnetic Resonance (COMPETE CMR). Circulation 2021, 143, 609-612. [CrossRef] [PubMed]

8. Ojha, V.; Verma, M.; Pandey, N.N.; Mani, A.; Malhi, A.S.; Kumar, S.; Sharma, S. Cardiac magnetic resonance imaging in coronavirus disease 2019 (COVID-19): A systematic review of cardiac magnetic resonance imaging findings in 199 patients. J. Thorac. Imaging 2021, 36, 73-83. [CrossRef] [PubMed]

9. Phelan, D.; Kim, J.H.; Elliott, M.D.; Wasfy, M.M.; Cremer, P.; Johri, A.M.; La Gerche, A. Screening of potential cardiac involvement in competitive athletes recovering from COVID-19 An expert consensus statement. J. Am. Coll. Cardiol. Img. 2020, 13, $2635-2652$. [CrossRef] [PubMed]

10. Daniels, C.J.; Rajpal, S.; Greenshields, J.T.; Rosenthal, G.L.; Chung, E.H.; Terrin, M.; Jeudy, J.; Mattson, S.E.; Law, I.H.; Borchers, J.; et al. Prevalence of Clinical and Subclinical Myocarditis in Competitive Athletes With Recent SARS-CoV-2 Infection. JAMA Cardiol. 2021. [CrossRef] [PubMed]

11. Gao, Y.; Chen, R.; Geng, Q.; Mo, X.; Zhan, C.; Jian, W.; Li, S.; Zheng, J. Cardiopulmonary exercise testing might be helpful for interpretation of impaired pulmonary function in recovered COVID-19 patients. Eur. Respir. J. 2021, 57, 2004265. [CrossRef] [PubMed]

12. Małek, Ł.A.; Marczak, M.; Miłosz-Wieczorek, B.; Konopka, M.; Braksator, W.; Drygas, W.; Krzywański, J. Cardiac involvement in consecutive elite athletes recovered from Covid-19: A magnetic resonance study. J. Magn. Reson. Imaging 2021, 53, 1723-1729. [CrossRef] [PubMed] 